\title{
Carbon Nanotube Synthesis and Dispersion Using Arc Discharge in Foam Made with a Surfactant*
}

\author{
Yongil $\mathrm{Kim}^{\dagger}$ and Eiichi Nishikawa \\ Department of Electrical Engineering, Tokyo University of Science, \\ Niijyuku 6-3-1, Katsushika, Tokyo 125-8585, Japan \\ Yasuyuki Watanabe \\ Department of Electrical and Electronic Engineering, Suwa University of Science, \\ 5000-1 Toyohira, Chino-City, Nagano 391-0292, Japan \\ (Received 9 January 2018; Accepted 14 August 2018; Published 1 September 2018)
}

\begin{abstract}
For the production of carbon nanotubes (CNTs), the underwater arc-discharge method, in comparison to the vacuum arc-discharge method, has some drawbacks, including weak discharge intensity, low discharge sustainability, and low production volumes of CNTs. Likewise, despite its advantages, there are also some disadvantages to the use of arc discharges in foams, as these require additional distillation processes to eliminate foam after CNT production. This study, therefore, investigates an alternative method, replacing conventional foams used as discharge environments with foam made from the surfactant sodium dodecyl sulfate (SDS). Our results indicate that by using an arc discharge in a $0.03 \%$ SDS solution, we succeeded in producing aggregated CNTs, and the synthesized CNTs had high linearity and crystallinity. Furthermore, dispersion of the CNTs produced by arc discharge in the surfactant foam was facilitated by ultrasonic processing. [DOI: 10.1380/ejssnt.2018.382]
\end{abstract}

Keywords: Carbon nanotubes; Arc discharge; Foam; Surfactant; Transmission electron microscope

\section{INTRODUCTION}

Carbon nanotubes (CNTs) are new allotropes of carbon that were discovered by Iijima in 1991 [1]. CNTs have superior properties compared to most other similar materials. For example, the tensile strength is approximately 100 times that of steel, heat conduction is approximately 10 times that of copper, and electrical conductivity is approximately 1000 times that of copper. CNTs are expected to have potential applications in a great variety of fields. They are $0.4-5.0 \mathrm{~nm}$ in diameter and are created when uniform graphite planes are rolled into tubular shapes after carbon combustion and redeposition processes. CNTs have a variety of advantages such as lightness, flexibility, high strength, and high conductivity, due to the arrangement of the graphite sheets, which consist of carbon atoms in a hexagon pattern, are wound and overlapped. Consequently, they are expected to have applications not only in biotechnology, but also as nextgeneration electrode materials [2-5].

In general, CNTs can be synthesized by any of the following techniques: the arc-discharge [6-13], laser-ablation [14-18], or chemical vapor deposition (CVD) methods [927]. The arc discharge releases electrons from the carbon in the cathode that collide with carbon on the anode, and the carbon on the anode tip becomes extremely hot and vaporizes. High-quality linear CNTs are produced when these carbon atoms recombine. However, the disadvantage of the arc discharge method is that device configuration for an arc discharge in a vacuum is complicated and costly [28]. Therefore, underwater (or liquid) arc discharge has been proposed as a method of synthesizing low cost CNTs using a simple equipment setup, without the

\footnotetext{
* This paper was presented at the 8th International Symposium on Surface Science, Tsukuba International Congress Center, Tsukuba, Japan, October 22-26, 2017.

$\dagger$ Corresponding author: kim@rs.tus.ac.jp
}

need for any vacuum apparatus [29-38].

Unfortunately, there are some disadvantages associated with the underwater arc-discharge method. Compared to its use in a vacuum, the underwater discharge environment affects the discharge intensity and sustainability, and therefore it is not suitable for efficient large-scale production of CNTs. To increase the discharge intensity and sustainability, and hence the potential for high-volume CNT production, the arc-discharge-in-foam method was proposed in which a discharge environment midway between the vacuum and underwater environments is utilized $[39,40]$.

Since the discharge environment in this method bears a closer resemblance to the vacuum environment than the underwater one, discharge intensity and sustainability are remarkably improved with respect to those properties of the underwater arc-discharge method. Furthermore, the arc-discharge-in-foam method does not require vacuum equipment since beer foam is used as the discharge environment, providing a simple device configuration. CNTs with high crystallinities can therefore be easily synthesized using this method. However, since beer foam is used as the discharge environment, distillation processes are required to eliminate beer foam following the production of the CNTs.

The production of CNTs by means of arc discharge tends to form bundles due to van der Waals forces, leading to difficulties in particle dispersion in water and generic solvents. Although there partial dispersion may be obtained using ultrasonic irradiation, water and organic solvents cannot adequately solvate CNTs; therefore, the bundled state returns as soon as the ultrasonic irradiation is stopped [41]. As a result, the CNT dispersion method, which adds anionic surfactant sodium dodecyl sulfate (SDS) to CNT solvents as a dispersant, and ultrasonication have been widely applied to address this concern $[42-45]$.

The purpose of this study, therefore, aims to simultaneously perform CNT production and dispersion pro- 


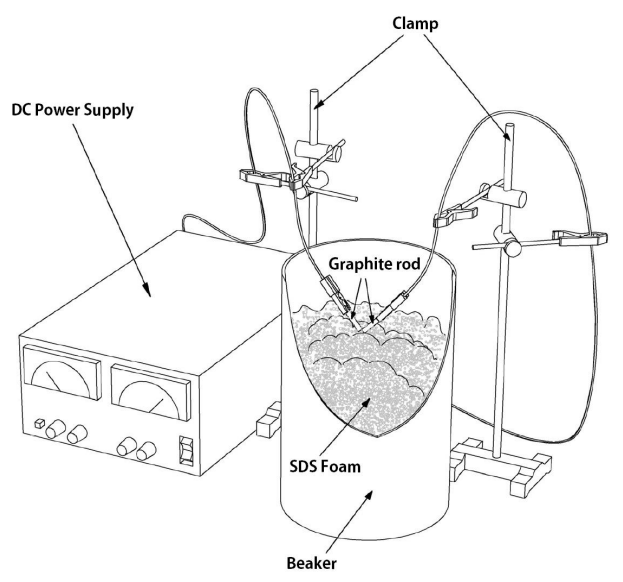

FIG. 1. A schematic of the experimental setup for the arcdischarge-in-foam method.

cesses. Experiments were conducted using a surfactant (SDS) as the discharge location in the arc-discharge-infoam method to observe the efficiency and feasibility of the production processes in relation to the application of conventional foam. Further analyses were performed to determine whether CNT syntheses and dispersion processes can be carried out simultaneously through the dispersion of synthesized CNT in SDS.

\section{EXPERIMENTAL}

Figure 1 shows a schematic of the experimental setup. For the arc discharge environment, a $500 \mathrm{~mL}$ beaker was filled with $300 \mathrm{~mL}$ of a surfactant $(0.03 \%$ in distilled water); Sodium dodecyl sulfate (SDS) was used. A regulated DC power supply (PDS20-36, Kenwood TMI Corp., Japan) was used as the direct current power source for the arc discharge. For the anodes of the arc discharge, carbon rods (4-mm-diameter carbon electrodes, Narika Co.) were used.

\section{A. Selecting the surfactant concentration of the SDS foam}

As shown in Fig. 2, in order to produce the surfactant foam, an optimal surfactant solution was selected by adjusting its concentration in $100 \mathrm{~mL}$ of distilled water, and comparing the breakdown of the foam at each concentration. The concentration was adjusted using $0.01 \mathrm{mg}$ of SDS dissolved in $100 \mathrm{~mL}$ of distilled water, in intervals from $0.01 \%$ to $0.05 \%$.

The surfactant foam was produced by continuously pumping air from a pump installed at the bottom of the beaker. Comparisons were then made between the time it took for the foam to reach the top of the beaker (Rising of Foam), and the time it took for the foam to recede from the top of the beaker to the 500-cc line (Descent of Foam).

At a concentration of $0.01 \%$, the foam took the longest and the shortest amount of time to both rise and descend, respectively. In addition, due to the low viscosity of the bubbles, the foam formation was difficult, and the foam

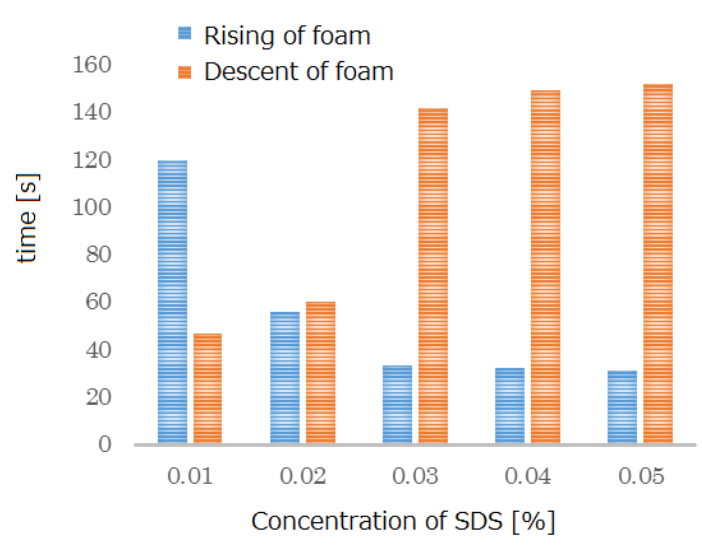

FIG. 2. Comparison of foam sustainability due to differences in the density of surfactants (blue: rising time, orange: descent time).

only lasted for a short period of time. At a concentration of $0.03 \%$ or higher, the foam took the shortest and the longest amount of time to rise and descend, respectively. Because the viscosity of the bubbles was relatively high, the feasibility of foam production improves with the foams lasting for longer periods of time. However, beyond a concentration of $0.03 \%$, the sustainability of the foam did not increase with higher concentrations. Therefore, we selected $0.03 \%$ as the concentration of surfactant for the next experiments.

\section{B. Arc discharge in surfactant foam method}

As shown in Fig. 3(a), the surfactant that had been adjusted to a concentration of $0.03 \%$ to optimize its viscosity was poured into a $500-\mathrm{mL}$ beaker. After filling the beaker with the surfactant foam, ensuring that the carbon electrodes were completely submerged, direct voltages of $20 \mathrm{~V}$ and $20 \mathrm{~A}$ were applied from a direct power supply and an arc discharge was maintained between the carbon electrodes for $30 \mathrm{~min}$, as shown in Fig. 3(b).

In general, arc discharges within bubbles cause the bubbles to expand due to the drastic increases in temperature that accompany arc discharges. Consequently, small bubbles burst, and the surface tension between them causes
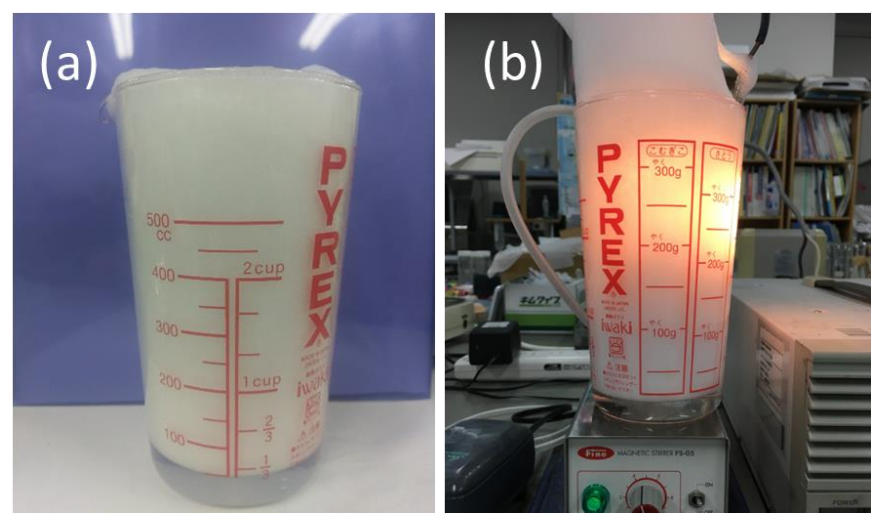

FIG. 3. Images showing foam in a surfactant concentration of $0.03 \%$ : (a) Surfactant foam. (b) Arc discharge in the surfactant foam. 

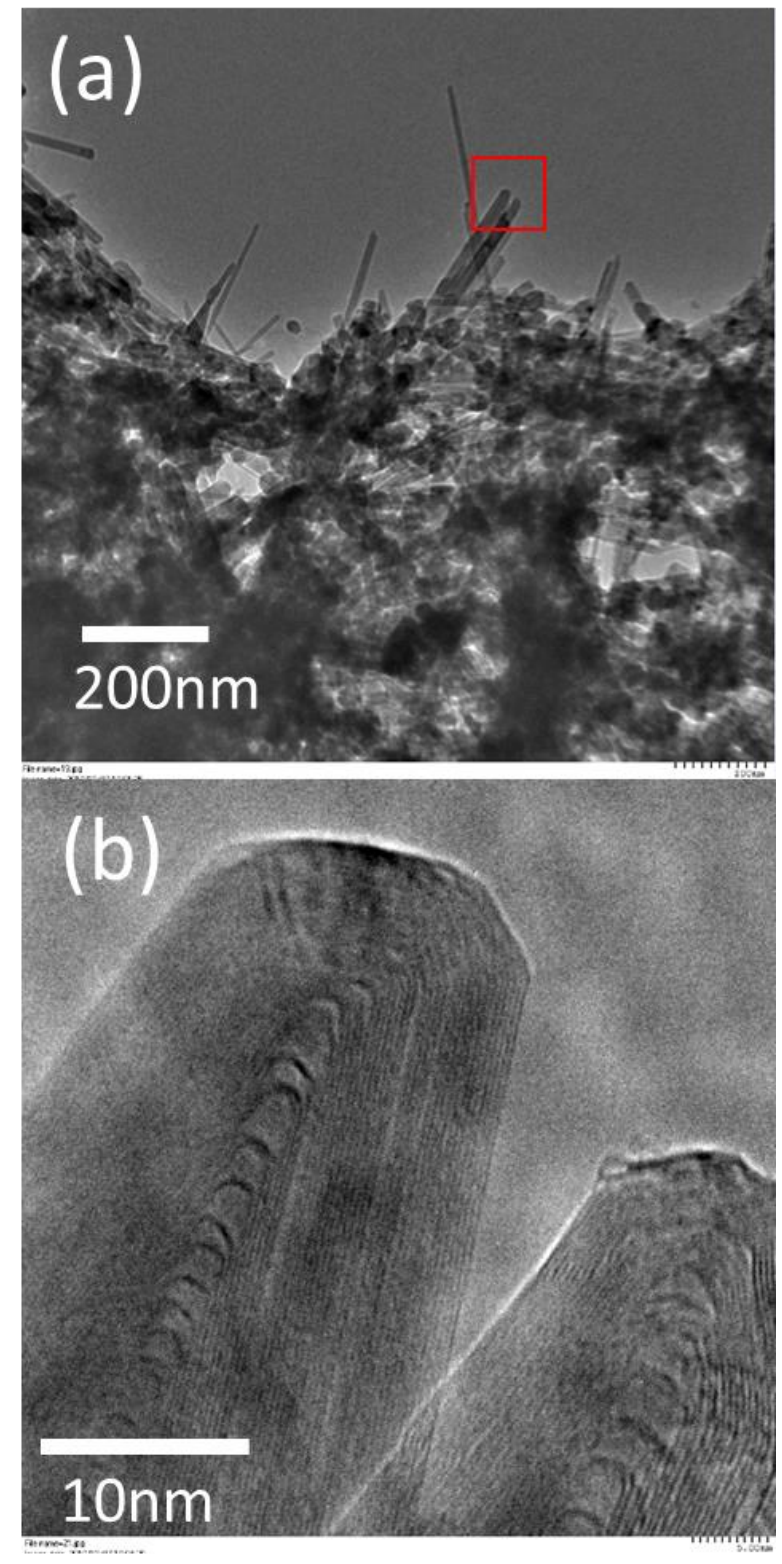

FIG. 4. (a) TEM image of CNTs produced in a surfactant foam before the ultrasonic processing. (b) A highermagnification image within the red square marked in (a).

them to re-combine with adjacent bubbles, so stable arc discharges are possible, even within bubbles, without the rupture of any bubbles in the discharge environment.

Following the discharge, we collected the product adhering to the surfactant foam and observed it via transmission electron microscopy (TEM). Meanwhile, ultrasonic processing was applied to the surfactant foam, following the discharge, to prepare a dispersion. The products within the dispersion were then observed using TEM.

\section{RESULTS AND DISCUSSION}

At first, we have observation of products that adhered to the surfactant foam. Figure $4(\mathrm{a}, \mathrm{b})$ shows the products synthesized using the arc discharge in the surfactant. As shown in Fig. 4(a), the CNTs were produced in tight formations. Furthermore, after magnifying and observing

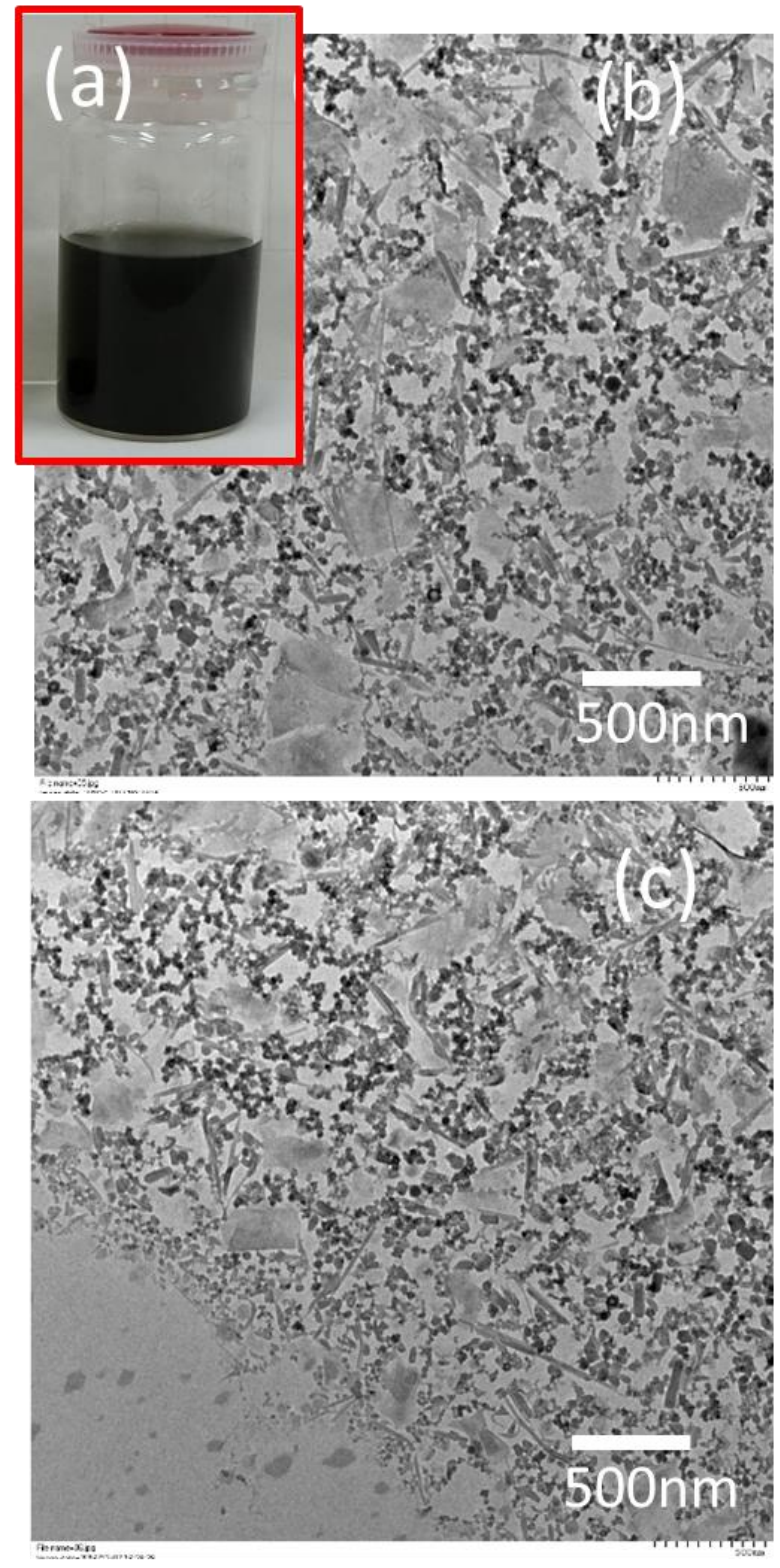

FIG. 5. Products imaged after ultrasonic processing in the surfactant foam: (a) Photograph of sample after ultrasonic processing. (b, c) TEM images of the same sample.

the area within the red square in Fig. 4(a), CNTs with high linearity and crystallinity may be observed, as shown in Fig. 4(b). Thus, CNTs with a high linearity and crystallinity were observed in the surfactant foam. However, CNT adhered to the foam of the surfactant was not completely dispersed, and CNT and fullerenes were observed in a dense state.

Next, following the dispersion processing of the samples created in the surfactant, after $1 \mathrm{~h}$ of the arch discharge, application of an ultrasonic cleaning device, and a further of $72 \mathrm{~h}$ elapsed, the dispersions were compared based on the precipitation of the products inside the samples, as shown in Fig. 5(a); the products in the surfactant sample after the ultrasonic processing had not settled, even after $72 \mathrm{~h}$ had elapsed. The liquid remained with a uniform, black color, and the products were uniformly dispersed in the liquid. TEM images of the sample products, after dispersion, are shown in Fig. 5(b, c), where it may be 
observed that each individual CNT, produced by arc discharge in the surfactant foam, was isolated and distinct in form.

Isolated individual CNTs and fullerenes within the products in the dispersion were observed multiple times. Our results indicate that sufficient product dispersion was achieved through ultrasonic processing of the surfactant foam.

By comparing the respective TEM images taken before or after dispersion processing, we observed that the CNTs in the surfactant had dispersed.

Generally, surfactant, causes CNTs to become hydrophilic through its surfactant action, which allows for easier dispersion [46-50]. Thus, surfactant foam which the presence of a surfactant in a gas-liquid system, the dispersion of the CNTs produced by the arc discharge in the surfactant foam became easier as a result of ultrasonic processing.

When samples of made in beer foam were stored as is, many different molds began to grow, within a matter of days; this makes it impossible to store the samples at room temperature. In contrast, no changes occurred in the samples of the CNTs produced in the surfactant foam, even after storage for several days at room temperature. Stable long-term storage is, therefore, possible under these conditions. Thus, even in cases where a surfactant-CNT dispersion is used for the preparation of CNT thin films, stable CNT thin films can be maintained for a long duration without any mold growing on the thin film.

\section{CONCLUSIONS}

By creating an arc discharge in the SDS surfactant distilled water solution, that had been adjusted to $0.03 \%$ concentration, we succeeded in producing aggregated CNTs, and we were also able to synthesize CNTs with high linearity and crystallinity in the surfactant foam. Furthermore, the dispersion of the CNTs produced by the arc discharge in the surfactant foam became easier as a result of ultrasonic processing.

This study also demonstrated that creating an arc discharge inside a surfactant foam allows for CNT production and dispersion to be performed in a single process, and that good-quality CNTs with high crystallinities can be produced with the utilization of simple equipment and configurations. Furthermore, it was observed from these experiments that CNTs can be produced and dispersed at the same time using a surfactant foam.

In future, we would like to perform further studies to determine whether it is possible to use dispersion liquid from the CNTs produced in the surfactant foam to manufacture CNT thin films. However, we note that one future challenge is to verify the quantitative distribution of the amount of CNTs produced using various voltages and currents for the arc discharge, since such discharges within the foam simultaneously produce other nanocarbon products such as fullerenes in addition to CNTs.
[1] S. Iijima, Nature 354, 56 (1991).

[2] J. Kong, H. T. Soh, A. M. Cassell, C. F. Quate, and H. Dai, Nature 395, 878 (1998).

[3] J. Hone, M. C. Llaguno, M. J. Biercuk, A. T. Johnson, B. Batlogg, Z. Benes, and J. E. Fischer, Appl. Phys. A 74, 339 (2002).

[4] J. A. Misewich, R. Martel, Ph. Avouris, J. C. Tsuang, S. Heinze, and J. Tersoff, Science 300, 783 (2003).

[5] H. Nishijima, S. Kamo, S. Akita, and Y. Nakayama, Appl. Phys. Lett. 74, 4061 (1999).

[6] N. Arora and N. N. Sharma, Diam. Relat. Mater. 50, 135 (2014).

[7] A. Thess, R. Lee, P. Nikolaev, H.-J. Dai, P. Petit, J. Robert, C.-H. Xu, Y. H. Lee, S. G. Kim, A. G. Rinzler, D. T. Colbert, G. E. Scuseria, D. Tománek, J. E. Fischer, and R. E. Smalley, Science 273, 483 (1996).

[8] C. Journet, W. K. Maser, P. Bernier, A. Loiseau, M. Lamyde la Chapelle, S. Lefrant, P. Deniard, R. Lee, and J. E. Fischerk, Nature 388, 756 (1997).

[9] T. Sugai, H. Omote, S. Bandow, N. Tanaka, and H. Shinohara, J. Chem. Phys. 112, 6000 (2000).

[10] M. Ohkohchi, Jpn. J. Appl. Phys. 38, 4158 (1999).

[11] Y. Saito, K. Kawabata, and M. Okuda, J. Phys. Chem. 99, 16076 (1995).

[12] Y. Ando and S. Iijima, Jpn. J. Appl. Phys. 32, L107 (1993).

[13] S. lijima, T. Ichihashi, and Y. Ando, Nature 356, 776 (1992).

[14] S. Lebedkin, P. Schweiss, B. Renker, S. Malik, F. Hennrich, M. Neumaier, C. Stoermer, and M. M. Kappes, Carbon 40, 417 (2000).

[15] N. Braidy, M. A. El Khakani, and G. A. Botton, Chem. Phys. Lett. 354, 88 (2002).
[16] T. Guo, P. Nilolaev, A. Thess, D. T. Colbert, and R. E. Smalley, Chem. Phys. Lett. 243, 49 (1995).

[17] W. K. Maser, E. Muñoz, A. M. Benito, M. T. Martínez, G. F. de la Fuente, Y. Maniette, E. Anglaret, and J.-L. Sauvajol, Chem. Phys. Lett. 292, 587 (1998).

[18] H. Zhang, Y. Ding, C. Wu, Y. Chen, Y. Zhu, Y. He, and S. Zhong, Physica B 325224 (2003).

[19] H. Dai, A. G. Rinzler, P. Nikolaev, A. Thess, D. T. Colbert, and R. E. Smalley, Chem. Phys. Lett. 260, 471 (1996).

[20] J. H. Hafner, M. J. Bronikowski, B. R. Azamian, P. Nikolaev, A. G. Rinzler, D. T. Colbert, K. A. Smith, and R. E. Smalley, Chem. Phys. Lett. 296, 195 (1998).

[21] H. M. Cheng, F. Li, X. Sun, S. D. M. Brown, M. A. Pimenta, A. Marucci, G. Dresselhaus, and M. S. Dresselhaus, Chem. Phys. Lett. 289, 602 (1998).

[22] Y. Li, W. Kim, Y. Zhang, M. Rolandi, D. Wang, and H. Dai, J. Phys. Chem. B 105, 11424 (2001).

[23] S. Tang, Z. Zhong, Z. Xiong, L. Sun, L. Liu, J. Lin, Z. X. Shen, and K. L. Tan, Chem. Phys. Lett. 350, 19 (2001).

[24] P. Nikolaev, M. J. Bronikowski, R. K. Bradley, F. Rohmund, D. T. Colbert, K. A. Smith, and R. E. Smalley, Chem. Phys. Lett. 313, 91 (1999).

[25] M. J. Bronikowski, P. A. Willis, D. T. Colbert, K. A. Smith, and R. E. Smalley, J. Vac. Sci. Technol. A 19, 1800 (2001).

[26] S. Maruyama , R. Kojima, Y. Miyauchi, S. Chiashi, and M. Kohno, Chem. Phys. Lett. 360, 229 (2002).

[27] W. Krätschmer, L. D. Lamb, K. Fostiropoulos, and D. R. Huffman, Nature 347, 354 (1990).

[28] N. Sano, H. Wang, M. Chhowalla, I. Alexandrou, and G. A. J. Amaratunga, Nature 414, 506 (2001).

[29] N. Sano, H. Wang, I. Alexandrou, M. Chhowalla, K. B. K. 
Teo, and G. A. J. Amaratunga, J. Appl. Phys. 92, 2783 (2002).

[30] H. Wang, M. Chhowalla, N. Sano, S. Jia, and G. A. J. Amaratunga, Nanotechnology 15, 546 (2004).

[31] N. Sano, Mater. Chem. Phys. 88, 235 (2004).

[32] N. Sano, J. Nakano, and T. Kanki, Carbon 42, 667 (2004).

[33] M. V. Antisari, R. Marazzi, and R. Krsmanovic, Carbon 41, 2393 (2003).

[34] B.-S. Xu, J.-J. Guo, X.-M. Wang, X.-G. Liu, and H. Ichinose, Carbon 44, 2631 (2006).

[35] X. Gang, J. Shenli, X. Jian, and S. Zongqian, Plasma Sci. Technol. 9, 770 (2007)

[36] M. Kobayashi, S.-M. Liu, S. Sato, H. Yao, and K. Kimura, Jpn. J. Appl. Phys. 45, 6146 (2006).

[37] S.-M. Liu, M. Kobayashi, S. Sato, and K. Kimura, Chem. Commun. 4690 (2005).

[38] M. Ishigami, J. Cumings, A. Zettl, and S. Chen, Chem. Phys. Lett. 319, 457 (2000).

[39] Y.-I. Kim, E. Nishikawa, and T. Kioka, e-J. Surf. Sci. Nanotech. 6, 167 (2008).

[40] Y. Kim, E. Nishikawa, and T. Kioka, IEEJ Trans. 4, 300 (2009).

[41] M. J. O'Connell, S. M. Bachilo, C. B. Huffman, V. C.
Moore, M. S. Strano, E. H. Haroz, K. L. Rialon, P. J. Boul, W. H. Noon, C. Kittrell, J. Ma, R. H. Hauge, R. B. Weisman, and R. E. Smalley, Science 297, 593 (2002).

[42] M. F. Islam, E. Rojas, D. M. Bergey, A. T. Johnson, and A. G. Yodh, Nano Lett. 3, 269 (2003).

[43] C. Richard, F. Balavonia, P. Schultz, T. W. Ebbesen, and C. Mioskowski, Science 300, 775 (2003).

[44] G. S. Duesberg, M. Burghard, J. Muster, G. Philipp, and S. Roth, Chem. Commun. 435 (1998).

[45] M. Burghard, G. Duesberg, G. Philipp, J. Muster, and S. Roth, Adv. Mater. 10, 584 (1998).

[46] S. Siljander, P. Keinanen, A. Raty, K. P. Ramakrishnan, S. Tuukkanen, V. Kunnari, A. Harlin, J. Vuorinen, and M. Kanerva, Int. J. Mol. Sci. 19, 1819 (2018).

[47] L. Vaisman, H. D. Wagner, and G. Marom, Adv. Colloid Interface Sci. 128-130, 37 (2006).

[48] A. J. Blanch, C. E. Lenehan, and J. S. Quinton, J. Phys. Chem. B 114, 9805 (2010).

[49] J. Yu, N. Grossiord, C. E. Koning, and J. Loos, Carbon 45, 618 (2007).

[50] M. F. Islam, E. Rojas, D. M. Bergey, A. T. Johnson, and A. G. Yodh, Nano Lett. 3, 269 (2003). 